\title{
Value-Based Care
}

Editor

LEE A. FLEISHER

\section{ANESTHESIOLOGY CLINICS}

www.anesthesiology.theclinics.com

Consulting Editor

LEE A. FLEISHER

December 2015 • Volume 33 • Number 4 